\title{
Paediatric gastroenterology: lessons of inborn errors
}

\author{
P.J. Milla
}

Senior Lecturer in Child Health, Honorary Consultant in Gastroenterology, Institute of Child Health (University of London), 30 Guilford Street, London WC1N 1EH, UK.

'It is even so - Nature is nowhere accustomed more openly to display her secret mysteries than in cases where she shows traces of her workings apart from the beaten path; nor is there any better way to advance the proper practice of medicine than to give our minds to the discovery of the usual law of nature, by careful investigation of cases of rarer forms of disease. For it has been found in almost all things, that what they contain of useful or applicable is hardly perceived unless we are deprived of them, or they become deranged in some way.' Thus wrote William Harvey to a Dutch physician who had sent him an unusual specimen. The doctrine of these clear thoughts were ever with Otto Wolff, and in fostering the development of paediatric gastroenterology he instilled first in John Harries and then in myself the usefulness and power of sophisticated biochemical and physiological investigation of the unusual patient. Careful investigation of such patients in the last twenty years has yielded much basic knowledge regarding intestinal digestion and absorption. During this period of time the techniques of per oral jejunal biopsy became widely used, the concept of sodium coupled active cotransport emerged and the enterocyte brush border was pin-pointed as the subcellular organelle concerned with digestion and absorption.

In this review I would like to highlight those contributions from our laboratory which, from the study of congenital or inherited defects of transport, have yielded fundamental information regarding intestinal absorptive processes.

\section{Small intestinal absorptive process}

In the course of the average day the human intestine handles large quantities of water, electrolytes and nutrients, the bulk of fluid entering the upper small intestine coming from various endogenous gastrointestinal secretions. The input of fluid into the adult jejunum each day has been estimated at 8 to 9 litres of water and $1200 \mathrm{mmol} \mathrm{Na}^{+}$, of which about 1 litre of water and $60-80 \mathrm{mmol}$ of $\mathrm{Na}^{+}$leaves the ileum to enter the colon (Phillips \& Giller, 1973) and only

Correspondence: P.J. Milla, M.Sc., F.R.C.P.
$150 \mathrm{ml}$ escapes as faeces. Thus the small intestine absorbs the bulk of water and electrolytes that enter it each day, mostly in the proximal jejunum, the ileum acting as a conservation and reserve area.

The intestinal mucosa is a complex epithelium in which water, electrolyte, nutrient absorption and secretion occur simultaneously. Absorption takes place primarily in the villous cells and secretion in the crypt cells (Field, 1978). The majority of water that is absorbed passes between cells, in response to osmotic gradients set up within the lateral intercellular spaces by the transcellular absorption of electrolytes and nutrients (Gupta et al., 1978). The transcellular absorption of highly polar aqueous electrolytes and nutrients requires the presence of specialized entry and exit mechanisms in the lipid rich apical brush border and basolateral enterocyte membranes, whereas nonpolar lipid nutrients are translocated by simple passive diffusion. Whilst the absorption of $\mathrm{Na}^{+}$and hence water has been incompletely characterized in man, it is clear that after a meal, the jejunum absorbs large quantities of water and electrolytes from a solution consisting mainly of isotonic bicarbonate, saline, and organic solutes produced during the process of digestion. Absorption of water and sodium can be promoted by the presence of certain organic solutes such as glucose and $\mathrm{HCO}_{3}{ }^{-}$ions. In addition to glucose the absorption of a wide variety of water-soluble organic solutes, including other D-hexoses, L-amino acids, diand tripeptides, some vitamins and, in the ileum only, bile salts (Schultz \& Curran, 1970). A model for $\mathrm{Na}^{+}$ coupled cotransport with organic solutes is shown in Figure 1. Absorption by this process can be considered a two-step process: coupled entry across the brush border via a carrier protein driven by the electrochemical gradient of $\mathrm{Na}^{+}$produced by the activity of a basolateral border $\mathrm{Na}^{+} \mathrm{K}^{+}$ATPase.

In addition to $\mathrm{Na}^{+}$coupled with organic solutes, $\mathrm{Na}^{+}$absorption may also be coupled to $\mathrm{Cl}^{-}$via a linked pair of exchangers $\mathrm{Na}^{+} / \mathrm{H}^{+}$and $\mathrm{Cl}^{-} / \mathrm{HCO}_{3}{ }^{-}$ (Figure 1), secreted $\mathrm{H}^{+}$and $\mathrm{HCO}_{3}^{-}$reacting in the lumen to form $\mathrm{H}_{2} \mathrm{O}$ and $\mathrm{CO}_{2}$. It is clear in both animals and humans that this system operates in the ileum. In the jejunum $\mathrm{HCO}_{3}{ }^{-}$in the lumen, which after a meal is derived from bile and pancreatic juice, promote $\mathrm{Na}^{+}$ and water absorption, making the double exchanger 

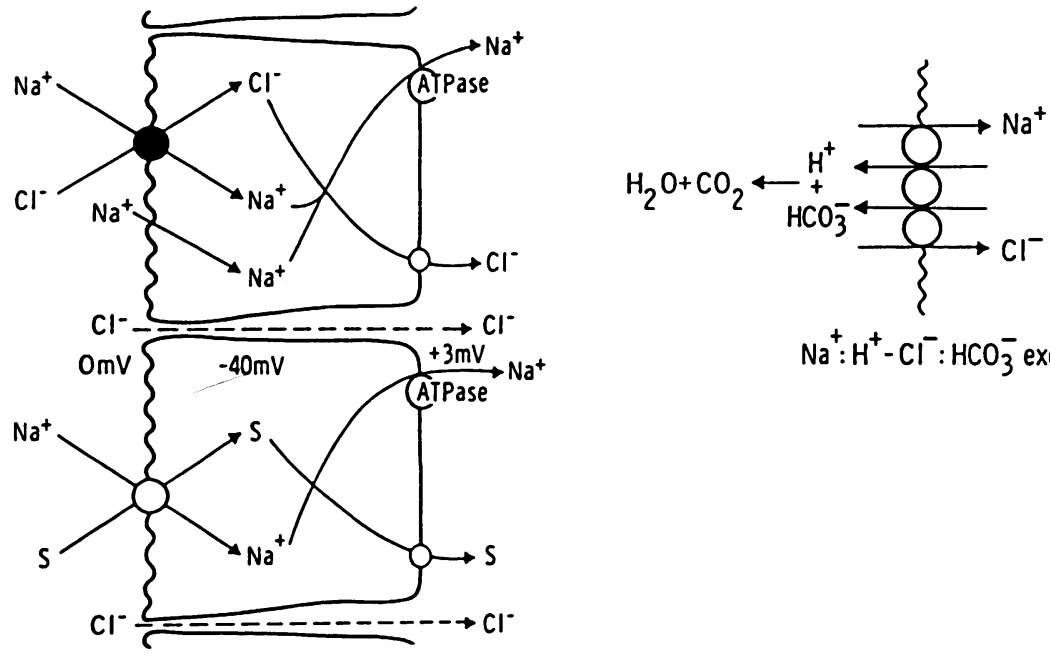

$\mathrm{Na}^{+}: \mathrm{H}^{+}-\mathrm{Cl}^{-}: \mathrm{HCO}_{3}^{-}$exchange

Figure 1 Absorptive mechanisms for $\mathrm{Na}^{+}$and organic solutes in small intestinal epithelium (left). $\mathrm{Na}^{+}$coupled $\mathrm{Cl}^{-}$absorption occurs via $\mathrm{Na}^{+} / \mathrm{H}^{+}-\mathrm{Cl}^{-} / \mathrm{HCO}_{3}{ }^{-}$exchangers (right). $\mathrm{S}=$ solutes; D-hexoses, L-amino acids, di-and tripeptides, and water soluble vitamins. (Courtesy W.B. Saunders Ltd.)

system outlined above seem unlikely. Whether the increased $\mathrm{Na}^{+}$absorption is due to transport of $\mathrm{HCO}_{3}{ }^{-}$across the mucosa, or whether it is the consequence of $\mathrm{H}^{+}$secretion with conversion of $\mathrm{HCO}_{3}{ }^{-}$to $\mathrm{CO}_{2}$ and $\mathrm{H}_{2} \mathrm{O}$ is not clear. Human perfusion experiments (Turnberg et al., 1970) suggest the latter.

There is considerable indirect evidence that the specialized entry or carrier mechanisms consist of transmembrane proteins whose mode of action is ill understood. It would seem, however, that the protein provides an entrance and exit gate, together with a channel in the membrane which allows particular ions and solutes to flow in particular directions. By analogy with other physiological functioning proteins, such as haemoglobin or enzyme proteins, alteration of the primary structure by as little as one amino-acid may significantly alter its function. For example, alteration of the hydrophobic parts of the molecule may affect the orientation of the molecule within the brush border membrane, with alteration of the direction of transport. Changes in the primary structure of the binding sites may affect the ability of the transporter protein to bind and release the ionic and solute species being translocated.

\section{Congenital defects of intestinal transport}

The study of patients with rare inherited defects of intestinal absorption involving glucose, amino acids and electrolytes, has provided evidence regarding the genetic control and heterogeneity of defective trans- porter proteins and the relative physiological importance of the particular transport process involved. The demonstration of many hundreds of inherited molecular variants of the globin moiety a d haemoglobin suggests that it is most unlikely that inherited abnormalities of intestinal absorption will be due to one single type of molecular abnormality.

\section{Defects of sodium and glucose transport}

Congenital glucose-galactose malabsorption A condition inherited in an autosomal recessive fashion, it was first described by two paediatric gastroenterologists, Lindquist \& Meeuwisse, in 1962. In the neonatal period, severe diarrhoea follows the introduction of milk feeds and unless glucose and galactose are withdrawn from the diet, the diarrhoea continues and may be fatal.

A number of studies both in vivo and in vitro, have been directed towards defining the basic abnormality in this condition. All have shown markedly impaired or absent sodium coupled absorption of glucose and galactose. The structural requirements for absorption by this system being a five carbon pyranose ring with, at carbon two, a hydroxyl group, below the horizontal plane of the ring. Thus hexoses, other than glucose and galactose, which share this configuration, such as 3-0methyl glucose and xylose, will be translocated, but hexoses such as fructose will not. Indeed our studies show that $\mathrm{Na}^{+}$coupled uptake of glucose is absent or impaired, but uptake of the amino acid L-leucine (Wimberley et al., 1974) and absorption of fructose 
(Milla et al., 1984) is intact. The presence of normal uptake of L-leucine suggests that alteration of the sodium gradient across the apical brush border is not basic to the defect in active hexose transport. The body of evidence suggests that the defect is one of brush border translocation with an absent or defective transporter protein.

Elsas et al. (1970) suggested from in vitro uptake studies of glucose in one family that the defect was due to a reduced number of normally functioning transporter proteins. Our earlier perfusion studies (Fairclough et al., 1978) failed to substantiate this. However, our more recent perfusion studies of five children (Milla $e t$ al., 1984) with this condition suggest that there may be a variety of defects involving glucose transport. In two of the five children, glucose absorption was markedly impaired and obeyed straight-line kinetics suggesting that the transporter protein was either absent or totally non-functional and absorption was by simple diffusion. In the remaining three children, glucose absorption, although markedly impaired, appeared to be by a saturable process with an apparent $\mathrm{Km}$ (appKm) the same as control subjects of about $75 \mathrm{mmol} / 1$ and a markedly reduced maximal velocity $\left(V_{\max }\right)$ of about $4 \mu \mathrm{mol} / \mathrm{min} / \mathrm{cm}$ compared to 25 in controls. These latter findings support Elsas' previous observation of markedly reduced numbers of normal transport sites and suggest, as might be expected, that there is genetic heterogeneity of congenital glucose-galactose malabsorption.

Our studies show that in one variant, there is either deletion of the transport protein or a totally nonfunctioning protein, and in another variant, very reduced numbers of normal transport proteins. In the latter group, one child was studied at 1 and 5 years of age, during which time some clinical glucose tolerance developed. No change in affinity for glucose, appKm 75 and $80 \mathrm{mmol} / 1$, was found but $\mathrm{V}_{\max }$ increased from 4.2 to $10.2 \mu \mathrm{mol} / \mathrm{min} / \mathrm{cm}$. These findings suggest that the improvement in symptoms with age that has been previously noted in congenital glucose-galactose malabsorption may be due to the development of greater numbers of normally functioning transport sites.

Mucosal disaccharidase activities are normal (Wimberley et al., 1974); on the basis of in vitro animal studies (Ramaswamy et al., 1976), absorption of glucose and galactose from dissaccharides by 'hydrolase related transport' might be expected to occur in glucose-galactose malabsorption. Our studies of glucose absorption from maltose (Fairclough et al., 1978) and Hughes \& Senior's (1975) studies using sucrose have failed to substantiate this. Furthermore, these studies have emphasized the nutritional importance of $\mathrm{Na}^{+}$coupled glucose and galactose absorption.
Congenital $\mathrm{Na}^{+}$secretory diarrhoea Congenital chloride-losing diarrhoea has until recently been the only defect of intestinal electrolyte transport which had been clearly defined. Infants with protracted lethal diarrhoea, which often occurs in families, may be examples of as yet undefined defects of electrolyte transport (Fordtran, 1967). Investigation of a child with such a secretory diarrhoea which started in utero led us to suspect a previously undescribed defect of $\mathrm{Na}^{+} / \mathrm{H}^{+}$exchange in the duodenum and jejunum (Milla et al., 1983). Development of a miniaturized technique for the preparation of brush border membrane vesicles from per oral jejunal biopsies in collaboration with the Institute of Physiology, Zurich, allowed us to study $\mathrm{Na}^{+} / \mathrm{H}^{+}$exchange in this child and control subejcts (Booth et al., 1985).

In control subjects we were able to demonstrate the presence of the two most important groups of translocation mechanisms for the absorption of $\mathrm{Na}^{+}$and hence water. $\mathrm{Na}$-coupled cotransport with organic solutes and $\mathrm{Na}^{+} / \mathrm{H}^{+}$exchange. Glucose uptake was enhanced some five-fold by $\mathrm{Na}^{+}$and vice versa. An outwardly directed $\mathrm{pH}$ gradient (in 6.0, out 7.4) increased $\mathrm{Na}^{+}$uptake seven-fold. Studies on two occasions of brush border membrane vesicles from the patient's biopsies showed normal glucose uptake but $\mathrm{H}^{+}$-dependent $\mathrm{Na}^{+}$uptake was only $12 \%$ of control values.

The studies highlighted above have not only described a new disease, but have shown the presence of $\mathrm{Na}^{+} / \mathrm{H}^{+}$exchange in the jejunum, and confirmed the importance of this mechanism and that of $\mathrm{Na}^{+}$ coupled with organic solutes in the overall conservation of water and $\mathrm{Na}^{+}$by the intestine.

\section{Defects of transport of divalent cations}

Whilst the absorption of nutrients and electrolytes has been extensively studied, the absorption of essential metals, apart from iron and calcium, and trace elements is not nearly so well understood. The careful study of patients with the rare genetically-determined conditions of acrodermatitis enteropathica and primary hypomagnesaemia have resulted not only in an understanding of the basic defect in these diseases but also has yielded fundamental information regarding the intestinal absorption of $\mathrm{Zn}^{++}$and $\mathrm{Mg}^{++}$ respectively.

Acrodermatitis enteropathica Acrodermatitis enteropathica (AE) is a disorder characterized by bullous skin lesions around the orifices, hair loss, and diarrhoea which is inherited in an autosomal recessive fashion. The importance of zinc in this disorder was first recognized by Moynahan and his colleagues at the Hospital for Sick Children in 1973 (Moynahan \& Barnes, 1973) and has led to a major breakthrough in 
our understanding of the physiological importance of zinc in man.

There is a considerable body of evidence to suggest that in $\mathrm{AE}$ the normal mechanism for zinc absorption is impaired. Using a metabolic balance technique (Aggett et al., 1978) we have shown that AE patients receiving no $\mathrm{Zn}^{++}$supplements are in a net secretory state with respect to $\mathrm{Zn}^{++}$which reverts to net absorption when oral supplements are given. In vitro jejunal biopsy studies allowed us to demonstrate that steady state uptake of ${ }^{65} \mathrm{Zn}$ in vitro is markedly reduced compared to controls and is equally apparent whether on or off zinc supplementation (Atherton $e t$ al., 1979). These data suggest defective entry of zinc into the enterocyte. Hambridge et al. (1978) found the $\mathrm{Zn}^{++}$content of jejunal mucosa in $\mathrm{AE}$ to be low, and reached the same conclusion.

\section{Primary hypomagnesaemia Primary hypomag-} nesaemia is inherited in an autosomal recessive fashion and presents in infancy with convulsions and tetany.

Magnesium balance studies (Paunier et al., 1968) have suggested a primary defect in intestinal absorption. Steady state perfusion studies (Milla et al., 1979) have now clearly demonstrated that the magnesium deficiency is related to a primary defect in magnesium transport. Net loss of magnesium into the intestinal lumen occurred when low ( 1 and 2 mmol/l) concentrations of $\mathrm{Mg}^{++}$were perfused in the jejunum compared to age matched controls. At high concentration $(10 \mathrm{mmol} / \mathrm{l})$ net absorption of $\mathrm{Mg}^{++}$similar in magnitude to controls occurred. Kinetic studies of the control subjects show that at least two separate transport mechanisms participate in the absorption of

\section{References}

AGGETT, P.J., ATHERTON, D.J., PELVES, H.T., THORN, J.M., BANGHAM, A., CLAYTON, B.E. \& HARRIES, J.T. (1978). Studies in acrodermatitis enteropathica, 3rd International Symposium on Trace Element Metabolism in Man and Animals, Kirchgessner, M. (ed). p. 418. Freising-Weihenstephan.

ATHERTON, D.J., MULlER, D.P.R., AGGETT, P.J. \& HARRIES, J.T. (1979). A defect in zinc uptake by jejunal biopsies in acrodermatitis enteropathica. Clinical Science., 56, 505.

BOOTH, I.W., STANGE, G., MURER, H., FENTON, T.K. \& MILLA, P.J. (1985). Defective jejunal brush border $\mathrm{Na}^{+} /$ $\mathrm{H}^{+}$exchange: a cause of congenital secretory diarrhoea. Lancet, i, 1066.

ELSAS, L.J., HILLMAN, R.E., PATTERSON, J.H. \& ROSENBERG, L.E. (1970). Renal and intestinal hexose transport in familial glucose-galactose malabsorption. Journal of Clinical Investigation, 49, 576.

FAIRCLOUGH, P.D., CLARK, M.L., DAWSON, A.M., SILK, B.D.A., MILLA, P.J. \& HARRIES, J.T. (1978). Absorption of
$\mathrm{Mg}^{++}$from the small intestine. A carrier-mediated system which saturates at low concentration (appKm$4.5 \mathrm{mmol} / 1$ and $V_{\max } 91 \mathrm{nmol} / \mathrm{min} / \mathrm{cm}$ ) and a simple passive diffusional process. In primary hypomagnesaemia the basic defect is an abnormality in carrier mediated transport from low intraluminal concentrations of magnesium.

The above studies of absorption in the small intestine of $\mathrm{Zn}^{++}$and $\mathrm{Mg}^{++}$suggest that there are at least two distinct and different mechanisms of absorption. At the relatively low intraluminal concentrations that result from normal levels of dietary ingestions, a carrier-mediated system presumably involving a transmembrane protein under genetic control, and at much higher intraluminal concentrations, a simple passive diffusional process which explains the ability of large oral doses of $\mathrm{Zn}^{++}$and $\mathrm{Mg}^{++}$to correct the deficiency state in these patients.

\section{Conclusion}

The unique experiments performed by nature and described here have yielded fundamental information regarding intestinal absorptive processes. The diseases themselves have highlighted the physiological importance of the absorptive process involved; the central role played by $\mathrm{Na}^{+}$in water conservation, not only bs $\mathrm{Na}^{+} / \mathrm{H}^{+}$exchange but also coupled to the aqueous digestive products of the food we eat. A thorough understanding of the nature of $\mathrm{Na}^{+}$coupled cotrans port has led to perhaps the most important therapeutic advance this century, oral rehydration solutions in the treatment of acute diarrhoea.

glucose and maltose in congenital glucose-galactose malabsorption. Paediatric Research, 12, 1112.

FIELD, M. (1978). Some speculations on the coupling between sodium and chloride transport processes in mammalian and teleost intertene. In Membrane Transport Processes, Hoffman, J.F. (ed). p. 227. Raven Press: New York.

FORDTRAN, J.S. (1967). Speculations on the pathogenesis of diarrhoea. Federation Proceedings, 26, 1405.

GUPTA, B.L., HALL, T.A. \& NAFTALIN, R.J. (1978) Microprobe measurement of $\mathrm{Na}, \mathrm{K}$ and $\mathrm{Cl}$ conc profiles in epithelial cells and inter-cellular spaces of rabbit ileum. Nature, 272, 70.

HAMBRIDGE, K.M., WALRAVENS, P.A. \& NELDNER, K.H. (978). Zinc and acrodermatitis enteropathica. In Zinc and Copper in Clinical Medicine, Hambridge K.M., Nichols, B.L. (eds). p. 81. Spectrum Publications: New York.

HUGHES, W.S. \& SENIOR, J.R. (1975). The glucose-galactose malabsorption syndrome in a 23 year old woman. Gastroenterology, 68, 142. 
LINDQUIST, B. \& MEEUWISSE, G.W. (1962). Chronic diarrhoea caused by monosaccharide malabsorption. Acta Paediatrica Scandinavica, 51, 674.

MILLA, P.J., AGGETT, P.J., WOLFF, O.H. \& HARRIES, J.T. (1979). Studies in primary hypomagnesaemia evidence for defective carrier mediated small intestinal transport of magnesium. Gut, 20, 1028.

MILLA, P.J., FENTON, T.R. \& HARRIES, J.T. (1983). Fetal secretory diarrhoea: a new congenital transport defect. Paediatric Research, 17, 421.

MILLA, P.J., WOZNIAK, E. \& FENTON, T.R. (1984). Glucose absorption in congenital glucose-galactose malabsorption: a kinetic basis for clinical remission. Gut, 25, A1155.

MOYNAHAN, E.J. \& BARNES, P.M. (1973). Zinc deficiency and a synthetic diet for lactose intolerance. Lancet, i, 676 .

PAUNIER, L., RODDE, I.C., KOOH, S.W. \& FRASER, D. (1968). Primary hypomagnesaemia with secondary hypocalcaemia in an infant. Pediatrics, 41, 285.
PHILLIPS, S.F. \& GILLER, J.E. (1973). The contribution of the colon to electrolytes and water conservations in man. Journal of Laboratory and Clinical Medicine, 81, 733.

RAMASWAMY, K., MALATHI, P. \& CRANE, R.K. (1976). Demonstration of hydrolase related glucose transport from disaccharides in brush border membrane vesicles prepared from guinea pig small intestine. Biochemical and Biophysical Research Communications, 68, 162.

SCHULTZ, S.G. \& CURRAN, P.F. (1970). Coupled transport of sodium and organic solutes. Physiological Reviews, 50, 637.

TURNBERG, L.A., FORDTRAN, J.S., CARTER, N.W. \& RECTOR, F.C. (1970). Mechanisms of bicarbonate absorption and its relationship to sodium transport in the human jejunum. Journal of Clinical Investigations, 49, 557.

WIMBERLEY, P.D., HARRIES, J.T. \& BURGESS, E.A. (1974). Congenital glucose-galactose malabsorption. Proceedings of the Royal Society of Medicine, 67, 755. 